\title{
MUPIROCIN RESISTANCE IN STAPHYLOCOCCUS AUREUS IN A TERTIARY CARE HOSPITAL OF SOUTH INDIA - A PROSPECTIVE STUDY
}

\author{
MALAVALLI VENKATESH BHAVANA ${ }^{1 *}$, SANGEETA JOSHI ${ }^{2}$, RANJEETA ADHIKARY ${ }^{1}$, HOSDURG BHASKAR BEENA ${ }^{1}$ \\ ${ }^{1}$ Department of Laboratory Medicine - Microbiology, Manipal Hospital, HAL Airport Road, Kodihalli, Bengaluru, Karnataka, India. \\ ${ }^{2}$ Department of Microbiology, NH SRCC Children's Hospital, Mumbai, Maharashtra, India. Email: bhavana224@gmail.com
}

Received: 07 July 2018, Revised and Accepted: 30 August 2018

\section{ABSTRACT}

Objective: Mupirocin is a topical antibiotic used for the treatment of skin and soft tissue infections caused by Staphylococcus aureus and for the nasal decolonization of methicillin-resistant $S$. aureus (MRSA). The increasing reports of resistance to mupirocin are a matter of concern. We undertook this study to detect and differentiate the mupirocin resistance pattern and to analyze the susceptibility pattern among $S$. aureus isolates of our hospital.

Methods: This is a prospective laboratory-based study conducted during the period May-September 2014. Clinical samples that grew S. aureus during the study period were tested for mupirocin resistance using the $5 \mu \mathrm{g}$ and $200 \mu \mathrm{g}$ discs. Minimum inhibitory concentration (MIC) detection of resistant strains was performed using the E-test.

Results: Mupirocin resistance was seen in $4.81 \%$ of our S. aureus isolates; all of which exhibited high-level resistance with MIC $\geq 1024 \mu \mathrm{g} / \mathrm{ml}$.

Conclusions: The resistance is bound to rise with the increased usage of mupirocin; regular testing will help in tackling this upcoming problem and in preserving this important antibiotic against MRSA.

Keywords: Staphylococcus aureus, Mupirocin, High- and low-level resistance.

(C) 2019 The Authors. Published by Innovare Academic Sciences Pvt Ltd. This is an open access article under the CC BY license (http://creativecommons. org/licenses/by/4. 0/) DOI: http://dx.doi.org/10.22159/ajpcr.2018.v12i1.21183

\section{INTRODUCTION}

Staphylococcus aureus is a common cause of skin and soft tissue infections worldwide. A significant number of these infections are caused by methicillin-resistant $S$. aureus (MRSA). Carriage of MRSA in nose, axilla, and perineum is an important risk factor for its acquisition. Vancomycin or linezolid is used for the treatment of MRSA whereas mupirocin is an effective topical antibiotic for its elimination in carriers $[1,2]$.

Mupirocin (pseudomonic acid A) is derived from Pseudomonas fluorescens. It is in use clinically since 1985. It specifically binds to bacterial isoleucyl tRNA synthetase (IRS) and inhibits protein synthesis. It is used for the treatment of skin and soft tissue infections caused by $S$. aureus. In addition, it is also in use as a nasal ointment for the elimination of MRSA colonization in healthcare workers and adult patients for the control of outbreaks [3].

The first report of mupirocin resistance came 2 years after its introduction [4]. Nasal application of mupirocin at clinically effective concentrations may result in the presence of low levels of the antibiotic in the pharynx, which could lead to resistant strains [5].

Mupirocin-resistant strains are grouped into two distinct categories: Those with low-level resistance showing minimum inhibitory concentrations (MICs) of 8-256 $\mu \mathrm{g} / \mathrm{ml}$ and strains with high-level resistance having MIC $\geq 512 \mu \mathrm{g} / \mathrm{ml}$. Susceptible strains are those with MIC $\leq 4 \mu \mathrm{g} / \mathrm{ml}$. Low-level resistance is due to the mutational change in the chromosomally encoded ileS-2 (mupA) gene [6]. This has been shown to develop in $S$. aureus isolates exposed in vitro to progressively higher concentrations of mupirocin [7]. The genetic basis for high-level resistance is the acquisition of a plasmid containing the mupA gene encoding an additional IRS enzyme [8]. It is also attributed to another gene $\operatorname{mup} B$ [9].

Resistance to mupirocin can be routinely detected in the laboratory by disc diffusion using $5 \mu \mathrm{g}$ and $200 \mu \mathrm{g}$ discs. The mere detection of resistance does not provide the complete picture; it is also necessary to determine the level of resistance. The concomitant use of the two discs can differentiate between low-level and high-level resistance. Isolates with a zone diameter of $\geq 14 \mathrm{~mm}$ for both $5 \mu \mathrm{g}$ and $200 \mu \mathrm{g}$ discs are considered to be susceptible for mupirocin. Isolates with zone diameter of $<14 \mathrm{~mm}$ in the $5 \mu \mathrm{g}$ disc but $\geq 14 \mathrm{~mm}$ in the $200 \mu \mathrm{g}$ disc are taken as low level resistant strains. All isolates with zone diameters $<14 \mathrm{~mm}$ for both $5 \mu \mathrm{g}$ and $200 \mu \mathrm{g}$ are considered to be high-level resistant strains [10]. In addition, E-test can be used to know the MIC of mupirocin. High-level resistance is associated with therapeutic failure, whereas low-level resistance can be overcome by recommending a higher than usual dosage [11].

Studies conducted in different parts of the world show varied rates of resistance: Turkey (45\%), Trinidad and Tobago (26.1\%), USA (13.2\%), Spain (11.3\%), China (6.6\%), and Korea (5\%) [12-17]. The resistance seems to be on the rise in the Indian scenario as well. Hence, we undertook this study to look into the prevalence of mupirocin resistance among the $S$. aureus isolates of our hospital, to determine the extent of resistance and to analyze the antibiotic susceptibility pattern of $S$. aureus.

\section{METHODS}

This is a prospective laboratory-based study. Clinical samples received in our laboratory which grew $S$. aureus during the period May-September 2014 were included in the study. The following samples grew $S$. aureus: Pus (70\%), ear, nose, and throat swabs (18\%), blood (5\%), respiratory samples $(3 \%)$, and other samples such as intravascular catheter tips, urine, and sterile body fluids (4\%). Blood culture was done using BacT/Alert 3D (BioMérieux, France). Intravascular catheter tips were processed by Maki's roll culture technique. The other samples were inoculated onto standard media using standard techniques. Following incubation, identification of $S$. aureus was done on the basis of the colony morphology, Gram's stain, catalase test, and the tube coagulase test. Antimicrobial susceptibility testing was performed by Kirby-Bauer disc diffusion method and interpreted as per the Clinical and Laboratory Standards Institute standards [18]. The following 
antibiotics were tested: Penicillin (10 units), gentamicin $(10 \mu \mathrm{g})$, cotrimoxazole $(1.25 / 23.75 \mu \mathrm{g})$, ciprofloxacin $(5 \mu \mathrm{g})$, erythromycin $(15 \mu \mathrm{g})$, clindamycin $(2 \mu \mathrm{g})$, linezolid $(30 \mu \mathrm{g})$, and teicoplanin $(30 \mu \mathrm{g})$. Detection of methicillin resistance was carried out using cefoxitin $(30 \mu \mathrm{g})$ discs. D zone test was done do determine inducible resistance to clindamycin. Vancomycin MIC was determined using the E-test. (BioMérieux, France) Mupirocin $5 \mu \mathrm{g}$ and $200 \mu \mathrm{g}$ discs were used for the detection of resistance. MIC determination of mupirocin-resistant strains was done using the E-test. Mupirocin sensitive and resistant isolate were included as controls in each batch of strains tested.

\section{RESULTS}

We had a total of 187 non-duplicate $S$. aureus isolates during the study period. This comprised 117 methicillin-sensitive $S$. aureus (MSSA) (62.5\%) and 70 MRSA (37.4\%) strains. Inducible clindamycin resistance was seen in $33(17.64 \%)$ isolates.

Out of the 187, 9 isolates showed mupirocin resistance (4.81\%), of which 4 were MRSA (2.13\%), and 5 isolates were MSSA (2.67\%). All the isolates showed high-level resistance, with MIC $\geq 1024 \mu \mathrm{g} / \mathrm{ml}$. 6 of these samples were from pus, 2 were from ear swabs, and one isolate was from a nasal swab.

\section{DISCUSSION}

Mupirocin resistance has been reported from many parts of the world with varied frequencies. It is still not a huge problem in the Indian scenario. Oommen et al. have reported 2 and $28 \%$ incidence of mupirocin resistance in MRSA and methicillin-resistant coagulasenegative Staphylococci (MRCoNS), respectively [19]. According to a study by Gadepalli et al. high-level and low-level resistance was detected in 10 (5\%) and 2 (1\%) S. aureus strains, respectively [20]. As per Jayakumar et al., mupirocin resistance was seen in 3.3\% of Staphylococcal isolates [21]. Rajkumari et al. did not detect any mupirocin resistance among MRSA isolates [22]. Kaur and Narayan conducted a study on detection of mupirocin resistance in S. aureus and CONS from the nasal swabs of 140 healthcare workers. They reported $100 \%$ sensitivity to mupirocin among MSSA and methicillin-sensitive coagulase-negative Staphylococcus isolates. The rates of resistance from MRSA and MRCoNS were $1.43 \%$ and $3.57 \%$, respectively [23]. A study by Chaturvedi et al. reported $18.3 \%$ mupirocin resistance in MRSA; there were almost an equal number of high- and low-level resistances seen in their study [24].

According to our study, mupirocin resistance was seen in $4.81 \%$ of our $S$. aureus isolates, all of which exhibited high-level resistance. The interesting finding of our study is the presence of mupirocin resistance in MSSA almost equal to that in MRSA. According to a study by Kim et al. mupirocin resistance was seen in 39 isolates of $S$. aureus $(7.8 \%)$ which comprised 30 (9.5\%) MRSA and 9 (4.9\%) MSSA [25]. Another study by McNeil et al. reported $14.7 \%$ incidence of mupirocin resistance among $S$. aureus. Molecular analysis showed that 15 isolates (11\%) carried mupA, and the gene was more common in MSSA (21.4\%) than MRSA (8.3\%; $\mathrm{p}=0.03$ ) [26]. This is an important finding to note as these MSSA strains which carry the resistance genes can serve as reservoirs. Studies suggest that the mupA gene is transferred from other Staphylococcus species to MRSA during mupirocin prophylaxis [27]. Thus, increasing prevalence of transferable mupirocin resistance is an important threat to its future use.

\section{CONCLUSION}

Mupirocin resistance in S. aureus is bound to rise due to its increasing use. Routine hospital screening for MRSA colonization may increase its usage which may further lead to resistance. The only alternative to mupirocin for nasal decolonization is retapamulin, which is under investigation [28]. Oral antibiotics for decolonization are to be considered only in conjunction with topical agents and when all other measures have failed [29]. Therefore, mupirocin is the cornerstone for the decolonization of MRSA, the current picture of its resistance seems to be just the tip of an iceberg; regular testing will help in tackling this upcoming problem and in preserving this important antibiotic against MRSA.

\section{AUTHOR'S CONTRIBUTION}

Dr. Malavalli Venkatesh Bhavana has conducted the study and has provided the concepts, design, literature search, intellectual content, performed data analysis, and manuscript preparation. Dr. Sangeeta Joshi has provided the concepts, design, study protocol, data, and intellectual content and has performed the manuscript review. Dr. Ranjeeta Adhikary and Hosdurg Bhaskar Beena have provided the concepts, data, and intellectual content and have performed the manuscript review.

\section{CONFLICTS OF INTEREST}

The authors declare that there are no conflicts of interest regarding the publication of this article.

\section{REFERENCES}

1. Cookson BD. The emergence of mupirocin resistance: A challenge to infection control and antibiotic prescribing practice. J Antimicrob Chemother 1998:41:11-8.

2. Husean IY, Al-Rahman A, Al-Obaidi IR. Optimizing nasal formulation for prevention of serious infections caused. Int J Pharm Pharm Sci 2015;7:496-503.

3. Patel JB, Gorwitz RJ, Jernigan JA. Mupirocin resistance. Clin Infect Dis 2009;49:935-41.

4. Rahman M, Noble WC, Cookson B. Mupirocin resistant Staphylococcus aureus. Lancet 1987;2:387.

5. Watanabe H, Masaki H, Asoh N, Watanabe K, Oishi K, Kobayashi S, et al. Low concentrations of mupirocin in the pharynx following intranasal application may contribute to mupirocin resistance in methicillin-resistant Staphylococcus aureus. J Clin Microbiol 2001;39:3775-7

6. Farmer TH, Gilbart J, Elson SW. Biochemical basis of mupirocin resistance in strains of Staphylococcus aureus. J Antimicrob Chemother 1992;30:587-96.

7. Casewell MW, Hill RL. In-vitro activity of mupirocin ("pseudomonic acid") against clinical isolates of Staphylococcus aureus. J Antimicrob Chemother 1985;15:523-31.

8. Gilbart J, Perry CR, Slocombe B. High-level mupirocin resistance in Staphylococcus aureus: Evidence for two distinct isoleucyl-tRNA synthetases. Antimicrob Agents Chemother 1993;37:32-8

9. Seah C, Alexander DC, Louie L, Simor A, Low DE, Longtin J et al. Mup B, a new high-level mupirocin resistance mechanism in Staphylococcus aureus. Antimicrob Agents Chemother 2012;56:1916-20.

10. De Oliveira NE, Cardozo AP, Marques Ede A, dos Santos KR, Giambiagi-deMarval M. Interpretive criteria to differentiate low-and high-level mupirocin resistance in Staphylococcus aureus. J Med Microbiol 2007;56:937-9.

11. Hudson IR. The efficacy of intranasal mupirocin in the prevention of staphylococcal infections: A review of recent experience. J Hosp Infect 1994;27:81-98.

12. Sareyyüpoğlu B, Ozyurt M, Haznedaroğlu T, Ardiç N. Detection of methicillin and mupirocin resistance in staphylococcal hospital isolates with a touchdown multiplex polymerase chain reaction. Folia Microbiol (Praha) 2008;53:363-7.

13. Orrett FA. The emergence of mupirocin resistance among clinical isolates of methicillin-resistant Staphylococcus aureus in Trinidad: A first report. Jpn J Infect Dis 2008;61:107-10.

14. Jones JC, Rogers TJ, Brookmeyer P, Dunne WM Jr., Storch GA, Coopersmith CM, et al. Mupirocin resistance in patients colonized with methicillin-resistant Staphylococcus aureus in a surgical intensive care unit. Clin Infect Dis 2007;45:541-7.

15. Daskalaki M, Otero JR, Chaves F. Molecular characterization of resistance to mupirocin in methicillin-resistant Staphylococcus aureus isolates in a tertiary hospital in Spain. J Antimicrob Chemother 2009;63:826-8.

16. Liu QZ, Wu Q, Zhang YB, Liu MN, Hu FP, Xu XG, et al. Prevalence of clinical meticillin-resistant Staphylococcus aureus [MRSA] with high-level mupirocin resistance in Shanghai and Wenzhou, China. Int J Antimicrob Agents 2010;35:114-8.

17. Yun HJ, Lee SW, Yoon GM, Kim SY, Choi S, Lee YS, et al. Prevalence and $\infty$ mechanisms of low- and high-level mupirocin resistance in staphylococci isolated from a Korean hospital. J Antimicrob Chemother 2003;51:619-23.

18. Performance Standards for Antimicrobial Susceptibility Testing; $24^{\text {th }}$ Informational Supplement, Clinical and Laboratory Standards 
Institute [CLSI] M100-S20. Vol. 30, No.1. Wayne, PA: Clinical and Laboratory Standards Institute; 2014

19. Oommen SK, Appalaraju B, Jinsha K. Mupirocin resistance in clinical isolates of staphylococci in a tertiary care centre in South India. Indian J Med Microbiol 2010;28:372-5.

20. Gadepalli R, Dhawan B, Mohanty S, Kapil A, Das BK, Chaudhry R, et al. Mupirocin resistance in Staphylococcus aureus in an Indian hospital. Diagn Microbiol Infect Dis 2007;58:125-7.

21. Jayakumar S, Meerabai M, Banu SS, Mathew R, Kalyani M, Lal Y B. Prevalence of high- and low level mupirocin resistance among staphylococcal isolates from skin infection in a tertiary care hospital. J Clin Diagn Res 2013;7:238-42.

22. Rajkumari N, Mathur P, Bhardwaj N, Gupta G, Dahiya R, Behera B, et al. Resistance pattern of mupirocin in methicillinresistant Staphylococcus aureus in trauma patients and comparison between disc diffusion and E-test for better detection of resistance in low resource countries. J Lab Phys 2014;6:91-5.

23. Kaur DC, Narayan PA. Mupirocin resistance in nasal carriage of Staphylococcus aureus among healthcare workers of a tertiary care rural hospital. Indian J Crit Care Med 2014;18:716-21.

24. Chaturvedi P, Singh AK, Singh AK, Shukla S, Agarwal L. Prevalence of mupirocin resistant Staphylococcus aureus isolates among patients admitted to a tertiary care hospital. N Am J Med Sci 2014;6:403-7.

25. Kim MN, Kim H, An D, Ji M, Lee M, Kim AR, et al. Mupirocin resistance among MRSA surveillance isolates from neonatal intensive care unit under 10 year search and destroy policy compared to. BMC Proc 2011;5 Suppl 6:171

26. McNeil JC, Hulten KG, Kaplan SL, Mason EO. Mupirocin resistance in Staphylococcus aureus causing recurrent skin and soft tissue infections in children. Antimicrob Agents Chemother 2011;55:2431-3.

27. Hurdle JG, O’Neill AJ, Mody L, Chopra I, Bradley SF. In vivo transfer of high-level mupirocin resistance from Staphylococcus epidermidis to methicillin-resistant Staphylococcus aureus associated with failure of mupirocin prophylaxis. J Antimicrob Chemother 2005;56:1166-8.

28. Satyam SM, Bairy KL, Pirasanthan R, Vishnav RL, Kashyap S. Influence of topical retapamulin (1\%) ointment, sofinox- Rd cream, sofinox cream $(2 \%)$, zinc fusidate cream $(2 \%)$ and zinc fusidate ointment $(2 \%)$ on nasal mucosal surface safety in New Zealand albino rabbits. Int J Pharm Pharm Sci 2015;7:183-6.

29. McConeghy KW, Mikolich DJ, LaPlante KL. Agents for the decolonization of methicillin-resistant Staphylococcus aureus. Pharmacotherapy 2009;29:263-80. 